\title{
Molecular cytogenetic characterization of the urethane-induced murine lung cell line LA-4 as a model for human squamous cell lung cancer
}

\author{
SHAYMAA AZAWI ${ }^{1}$, MILASH BALACHANDRAN $^{1}$, FRITZ KRAMER $^{1}$, \\ STEFANIE KANKEL ${ }^{1}$, MARTINA RINCIC ${ }^{2}$ and THOMAS LIEHR ${ }^{1}$ \\ ${ }^{1}$ Institute of Human Genetics, Jena University Hospital, Friedrich Schiller University, D-07747 Jena, Germany; \\ ${ }^{2}$ Croatian Institute for Brain Research, School of Medicine University of Zagreb, 10000 Zagreb, Croatia
}

Received April 29, 2021; Accepted September 7, 2021

DOI: $10.3892 / \mathrm{mco} .2021 .2440$

\begin{abstract}
The murine tumor cell line LA-4 (also known as LA4 or LA 4) has been extensively used in $~ 70$ studies from 1975 to present. However, the genetic characteristics have not been comprehensively delineated, apart from a single solid-stain cytogenetic study, which reported an average of 116 chromosomes per cell. LA-4 was created via urethane induction in an $\mathrm{A} / \mathrm{He}$ mouse and demonstrated characteristic features of lung adenoma cells. In the present study, multicolor banding-based molecular cytogenetics was combined with molecular karyotyping to characterize ploidy, copy number alterations and chromosomal breakpoints of LA-4. A hyper-tetraploid karyotype with 85-93 chromosomes per cell, three distinct (pseudo-) dicentric derivatives, two neocentrics, four unbalanced translocations, two chromosomes with terminal deletions and one chromosome with a balanced inversion were detected. The results were translated into the human genome and a comparison with the literature revealed that LA-4 is well-suited as a murine model for human squamous cell lung cancer.
\end{abstract}

\section{Introduction}

Human lung malignancies are one of the leading causes of cancer-associated death and account for $\sim 17 \%$ of annual new tumor diagnoses worldwide. Lung cancers are categorized into the following subtypes: Lung squamous cell lung carcinoma (L-SCC; accounting for $\sim 30 \%$ ) and non-SCCs, which include e.g., lung adenocarcinomas (L-AC; 40\%) and large cell carcinomas $(\sim 10 \%)(1,2)$. Approximately $90 \%$ of L-SCCs

Correspondence to: Dr Thomas Liehr, Institute of Human Genetics, Jena University Hospital, Friedrich Schiller University, Am Klinikum 1, D-07747 Jena, Germany

E-mail: thomas.Liehr@med.uni-jena.de

Key words: lung cancer, adenoma, murine cell line LA-4, murine multicolor banding, array comparative genomic hybridization are induced by mutagens, particularly toxins inhaled during smoking $(1,3)$.

Accordingly, clinicians and oncologists are confronted with high numbers of lung cancer patients seeking treatment and cure. There are numerous therapeutic options available, including cytotoxic chemotherapy with carboplatin or cisplatin, or erlotinib or cetuximab to target epidermal growth factor, ipilimumab or nivolumab (inhibitors of the immune system) and ramucirumab (antiangiogenetic mechanism of action) (1). Ongoing research aims to target and interfere with additional metabolic pathways in cancer cells to increase sensitivity and response to therapies in lung cancer patients; numerous studies were performed using murine lung cancer cell lines (4-6).

The majority of commonly used murine cancer cell lines were established decades ago. More uniform in shape than human chromosomes, murine chromosomes are difficult to characterize by banding cytogenetics, which resulted in a lack of detailed genetic characterization despite the widespread use of these cell lines $(7,8)$. The urethane-induced murine lung cancer cell line LA-4 (also known as LA4 or LA 4), utilized in 70 studies in the literature, exemplifies the cytogenomic under-characterization of murine tumor cell lines. LA-4 was established in 1975 (9) from a lung adenoma induced in a (most likely female) $\mathrm{A} / \mathrm{He}$ mouse. Cells from a primary tumor were cultured and 50 cells were cytogenetically analyzed; on average, 114 (range, 54-133) chromosomes per metaphase were counted. Stoner et al (9) reported that the subclones LA-1 to LA-6 were established from the primary tumor; however, further details were only reported for LA-4 and at present, the other 5 cell lines are no longer available. Reports of LA-4 documented epithelial morphology with slower growth compared to the primary tumor. In addition, LA-4 cells did not have any tumorigenic potential in nude mice. Solid-stain cytogenetics revealed 116 (range, 87-132; 80\% of cells within the range of 106-122) chromosomes (9). According to the American Type Culture Collection (ATCC) webpage (accessed from Germany, but cell stocks are the same worldwide if purchased from ATCC, https://www.lgcstandards-atcc.org/ Products/All/CCL-196.aspx?geo_country=de\#characteristics), LA-4 cells have 38-256 chromosomes per cell, with rearranged chromosomes in $\sim 12 \%$ of the metaphases. 
As comprehensive cytogenomic characterization of murine tumor cell lines may be performed using murine multicolor banding (mcb) combined with molecular karyotyping (8), the present study provided the first karyotype (including ploidy level) for the LA-4 cell line, with an overview of chromosomal imbalances and in silico translation to regions of homology within the human genome; thus, it was possible to determine for which human tumor type this cell line may be used as model.

\section{Materials and methods}

Cell line. The murine LA-4 cell line (no. CCL-196 ${ }^{\mathrm{TM}}$; ATCC), were grown via adherent culture as per the supplier's protocol in Ham's F-12K medium, supplemented with fetal bovine serum and dimethyl sulfoxide (all from Thermo Fisher Scientific, Inc.). Subsequently, tandem cytogenetic analysis and whole genomic DNA extraction were performed (10) and analyses were performed as outlined below.

Molecular cytogenetics and karyotyping. Fluorescence in situ hybridization (FISH) was performed as previously described using whole-chromosome paints ('SkyPaint ${ }^{\mathrm{TM}}$ DNA kit M-10 for Mouse Chromosomes'; Applied Spectral Imaging) for multicolor-FISH and murine chromosome-specific mcb probe mixes for FISH-banding (10). At least 30 metaphases were analyzed for each probe set (Zeiss Axioplan microscopy; Zeiss AG), equipped with ISIS software v2.86 (MetaSystems). Array comparative genomic hybridization $(\mathrm{aCGH})$ was performed via standard procedures using the 'SurePrint G3 Mouse CGH Microarray, 4x180K' (Agilent Technologies, Inc.) (10).

Data analysis. Imbalances and breakpoints of LA-4 were determined from the mcb and $\mathrm{aCGH}$ data and aligned to human homologous regions using Ensembl (https://www.ensembl. org/info/website/tutorials/grch37.html) and the University of California Santa Cruz (UCSC) Genome Browser (http://genome-euro.ucsc.edu/cgi-bin/hgGateway?hgsid $=95241316 \&$ clade $=$ vertebrate $\&$ org $=$ Human $\& \mathrm{db}=$ hg $18 \&$ re direct=manual \&source=genome.ucsc.edu; GRCh37/hg19), as previously described (10). The data were compared to genetic changes associated with human cancers $(2,11,12)$.

\section{Results}

FISH and aCGH. The LA-4 cell line had a hyper-tetraploid karyotype with several numerical and structural aberrations. The following karyotype was observed in $88 \%$ of cells (Fig. 1): 85 93<4n>,X, dic $(X ; 5)(X q t e r->X A 1:: 5 G 2->5 q t e r),-X,-X,-4,-4$, $\operatorname{der}(4) \mathrm{t}(3 ; 4)(\mathrm{G} ; \mathrm{E} 2), \operatorname{der}(5) \mathrm{t}(4 ; 5)(\mathrm{A} 4 ; \mathrm{C} 3), \operatorname{del}(5)(\mathrm{G} 2), \operatorname{inv}(6)(\mathrm{A} 1 \mathrm{C})$, + neo(7)(:F3->qter),+dic(7;11)(7A1->7F3::11A2->11qter),+8,+8, $\operatorname{del}(10)(\mathrm{B} 5),+\operatorname{idic}(10)(\mathrm{A} 1 ; \mathrm{A} 1) \times 3$, neo(11)(:B3->qter),-13,-14,+15, $+\operatorname{der}(15) \mathrm{t}(13 ; 15)(\mathrm{C} 2 ; \mathrm{D} 3),+17,+17, \operatorname{der}(18) \mathrm{t}(6 ; 18)(\mathrm{B} 1 ; \mathrm{E} 3) \mathrm{x} 2,+19$, $+19,+19$.

In $12 \%$ of LA-4 cells, identical structural aberrations, but random loss of single chromosomes was observed; chromosome numbers ranged from 67 to 72 . Preferentially lost chromosomes were 1, 2, 6, 9, 15, 18 and 19.

Overall, the FISH results agreed with the aCGH-results, as summarized in Fig. 2A. In silico translation to the human genome (only imbalances $>3.5$ mega base pairs were included) identified the corresponding homologous regions (Fig. 2B). Details of aCGH and translation of data are summarized in Table SI; the original data of the aCGH experiment are provided in Table SII.

Comparison with the literature. The corresponding translated homologous copy number variations (CNVs) for LA-4 (Fig. 2B) were compared with common imbalances in related human cancers $(2,11,12)$ (Table I). In human L-AC, only 16/36 regions (44\%) were affected by CNVs, similar to the cell line LA-4. Of note, 18/36 (50\%) and 21/36 (58\%) of CNVs were concordant with human L-SCCs and head and neck SCC (HNSCC).

\section{Discussion}

The LA-4 cell line is derived from a mutagen (urethane)-induced primary tumor. In 1975, LA-4 cells were demonstrated to have a karyotype with $87-132$ chromosomes and $80 \%$ of the cells had chromosome numbers ranging from 106-122; no obvious structural aberrations were observed at that time (9). The only other cytogenetic analyses performed revealed structural aberrations in $12 \%$ of the cells with chromosome numbers ranging from 38 to 256 (https://www. lgcstandards-atcc.org/Products/All/CCL-196.aspx?geo_country $=$ de\#characteristics).

In the present study, the majority of LA-4 cells had 85 to 93 chromosomes, i.e., a hyper-tetraploid karyotype. There were three distinct (pseudo-)dicentric derivatives, two neocentrics, four unbalanced translocations, two chromosomes with terminal deletions and one chromosome with a balanced inversion. Thus, it was not possible to confirm the original observation that LA-4 harbored no structural rearrangements (9). Also, in contrast to the information from ATCC, these derivative chromosomes were present in $100 \%$ and not limited to only $12 \%$ of the cells, a result confirmed by the aCGH results (https://www.lgcstandards-atcc.org/Products/All/CCL-196.aspx? geo_country=de\#characteristics). However, as observed by Stoner et al (9), there was a small subpopulation with only 67-72 chromosomes per cell. The observed dicentric and neocentric chromosomes are unusual and only rarely reported as stable derivatives in tumor cell lines; of note, they have also been observed in human cancer cell lines (13). In previous studies of 23 murine tumor cell lines, these phenomena were only observed in the colorectal cancer cell line CMT-93 [for an overview see (14)].

These results indicate that LA-4 underwent a karyotype evolution during the past 46 years of cell culture. However, the LA-4 cells examined in the present study had an overall stable karyotype, with a tendency towards chromosomal loss in $\sim 12 \%$ of cells. Of note, tetraploidization was an early event that was present in the original tumor (9). Previously documented cell line evolution, e.g., for HeLa (15), suggests that variant clones of LA-4 may be present in different laboratories. Thus, it is highly recommended that an aCGH or cytogenetic study of the locally available and used LA-4 cells is performed to compare their chromosomal/genetic constitution with that reported in the present study prior to further experimentation. 


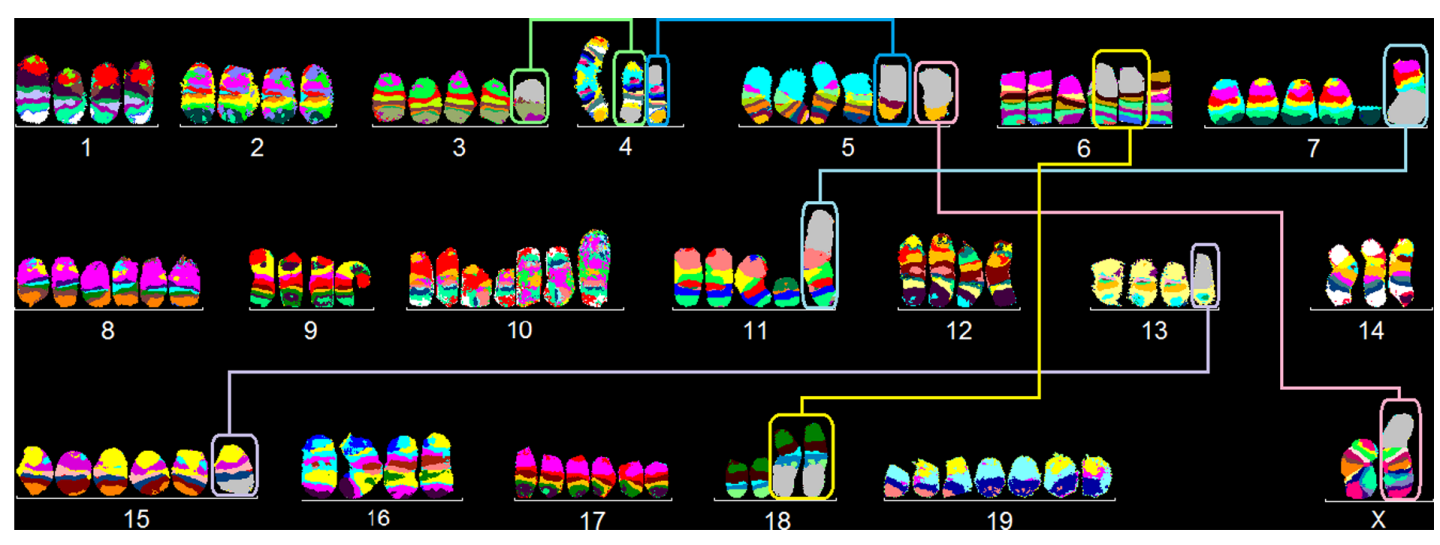

Figure 1. Summary of 19 chromosome-specific murine multicolor banding experiments applied in the LA-4 cell line depicted as pseudo-color banding. Derivative chromosomes consisting of different chromosomes are highlighted by frames and displayed twice in this summary karyogram.



Figure 2. Summary of array comparative genomic hybridization results and copy number variations detected in the cell line LA-4, depicted with respect to a diploid-basic karyotype. Gains are indicated as green bars, losses in red and breaks with arrows. (A) Imbalances observed in the cell line depicted along a murine chromosome set. (B) Results translated and projected along the human chromosome set.

LA-4 was established from a benign lung cancer, an adenoma. As reported in the present study, these genetic data establish that LA-4 cells have evolved in vitro, through the acquisition of compounding genetic changes, which were not initially present in 1975 (9). However, the comparison in Table I, which aligned LA-4 with specific human lung tumor types, was rather inconclusive at first observation. Aberrations typical for human L-ACs were $44 \%$ concordant and human L-SCCs were $\sim 50 \%$ concordant. Of note, LA- 4 cells exhibited $\sim 58 \%$ concordance with imbalances observed in human HNSCCs. Thus, it may be cautiously proposed that LA- 4 cells demonstrate characteristic (genetic) features most consistent 
Table I. Copy number changes associated with molecular subtypes of human L-AC, L-SCC and $\operatorname{HNSCC}(2,11,12)$ compared to those in LA-4 (translated to human).

\begin{tabular}{|c|c|c|c|c|}
\hline Chromosomal region & LA-4 & Human L-AC & Human L-SCC & Human HNSCC \\
\hline $1 \mathrm{p} 31.3-\mathrm{p} 22.3$ & Gain & Gain & Loss & Loss \\
\hline $2 \mathrm{p} 23 \sim 2 \mathrm{q} 12$ & Gain & (Gain) & Gain & Gain \\
\hline 3 pter $\sim$ p24.3 & Gain & - & Loss & Loss \\
\hline $3 \mathrm{p} 21.2-3 \mathrm{p} 12$ & Loss & - & Loss & Loss \\
\hline$\sim 4$ & Gain & Gain & Loss & - \\
\hline$\sim 5 p$ & Gain & Gain & Gain & Gain \\
\hline $5 q 14 q 14$ & Loss & Gain & Loss & Loss \\
\hline $5 q 15 \sim q 22$ & Gain & Gain & Loss & Loss \\
\hline 6pter-p22.1 & Loss & Gain & Gain & Gain \\
\hline $6 \mathrm{p} 22.1-6 \mathrm{q} 12$ & Gain & Gain & Gain & Gain \\
\hline $6 q 15-q 15$ & Loss & Loss & Gain & Loss \\
\hline 6q16.3-qter & Gain & (Loss) & Gain & Gain \\
\hline$\sim 7$ pter-p14 & Gain & Gain & Gain & Gain \\
\hline 7p14-p10 & Loss & Gain & Gain & Gain \\
\hline$\sim 7 q$ & Gain & Gain & Gain & Gain \\
\hline$\sim 8 \mathrm{p}$ & Gain & - & Loss & - \\
\hline$\sim 8 \mathrm{q} 12-\mathrm{q} 22.1$ & Loss & Gain & Gain & Gain \\
\hline $8 \mathrm{q} 22.1$-qter & Gain & Gain & Gain & Gain \\
\hline $9 \mathrm{q} 21.2-\mathrm{q} 22.3$ & Loss & - & Gain & Gain \\
\hline$\sim 10 \mathrm{q}$ & Gain & - & Loss & Gain \\
\hline$\sim 11$ pter-q14.3 & Gain & Gain & - & Gain \\
\hline 12 pter-q23 & Gain & Gain & Gain & Gain \\
\hline $12 \mathrm{q} 23$-qter & Loss & Gain & - & Gain \\
\hline$\sim 13$ & Loss & Gain & Loss & Gain \\
\hline $14 q 10-q 12$ & Loss & Gain & Gain & Gain \\
\hline $14 q 22-q 23$ & Loss & Gain & - & Gain \\
\hline $15 \mathrm{q} 25$-qter & Gain & - & Gain & Gain \\
\hline$\sim 16$ & Gain & Gain & Gain & Gain \\
\hline$\sim 17 \mathrm{p}$ & Gain & Loss & Loss & Gain \\
\hline$\sim 17 \mathrm{q}$ & Gain & Gain & Gain & Gain \\
\hline 18pter-p11.2 & Gain & - & Gain & Gain \\
\hline $18 \mathrm{q} 22$-qter & Loss & Loss & Loss & Gain \\
\hline$\sim 19$ & Gain & - & Gain & Gain \\
\hline 21q22.3-qter & Gain & - & - & Gain \\
\hline$\sim 22$ & Gain & - & Gain & Gain \\
\hline Overall & & $16 / 36$ & $18 / 36$ & $21 / 36$ \\
\hline
\end{tabular}

L-AC, lung adenocarcinomas; LSCC, lung squamous cell carcinoma; HNSCC, squamous cell carcinoma of head and neck.

with human SCC cells. As their lung origin is indubitable and they are mutagen-induced, similar to the majority of human L-SCCs, LA-4 may be considered a well-suited model for non-metastatic human L-SCC.

\section{Acknowledgements}

The technical support from Dr Nadezda Kosyakova (Jena University Hospital, Friedrich Schiller University, Institute of Human Genetics, Jena, Germany) and the help of Dr Heather E. Williams (Columbia University Irving Medical Center, Department of Pathology \& Cell Biology, New York, USA) in revising the English language of the manuscript are gratefully acknowledged.

\section{Funding}

The present study was supported by the Wilhelm Sander Stiftung (grant no. 2013.032.1).

\section{Availability of data and materials}

All data generated or analyzed during this study are included in this published article and in Tables SI and SII. 


\section{Authors' contributions}

TL conceived the study and obtained funding. SA, MB, FK and SK performed the FISH analysis. MR performed the aCGH study and pre-evaluation. SA performed the overall data interpretation. TL and SA checked and approved the authenticity of the raw data and drafted and edited the manuscript. All authors read and agreed to the final draft of the manuscript.

\section{Ethics approval and consent to participate}

Not applicable.

\section{Patient consent for publication}

Not applicable.

\section{Competing interests}

The authors declare that they have no competing interests.

\section{References}

1. Derman BA, Mileham KF, Bonomi PD, Batus M and Fidler MJ: Treatment of advanced squamous cell carcinoma of the lung: A review. Transl Lung Cancer Res 4: 524-532, 2015.

2. Yakut T, Schulten HJ, Demir A, Frank D, Danner B, Egeli U, Gebitekin C, Kahler E, Gunawan B, Urer N, et al: Assessment of molecular events in squamous and non-squamous cell lung carcinoma. Lung Cancer 54: 293-301, 2006.

3. Barbone F, Bovenzi M, Cavallieri F and Stanta G: Cigarette smoking and histologic type of lung cancer in men. Chest 112: 1474-1479, 1997.

4. Nurwidya F, Andarini S, Takahashi F, Syahruddin E and Takahashi K: Implications of insulin like growth factor 1 receptor activation in lung cancer. Malays J Med Sci 23: 9-21, 2016.
5. Hashemi-Sadraei N and Hanna N: Targeting FGFR in squamous cell carcinoma of the lung. Target Oncol 12: 741-755, 2017.

6. Tan AC: Targeting the PI3K/Akt/mTOR pathway in non-small cell lung cancer (NSCLC). Thorac Cancer 11: 511-518, 2020.

7. Leibiger C, Kosyakova N, Mkrtchyan H, Glei M, Trifonov V and Liehr T: First molecular cytogenetic high resolution characterization of the NIH $3 \mathrm{~T} 3$ cell line by murine multicolor banding. J Histochem Cytochem 61: 306-312, 2013.

8. Azawi S, Liehr T, Rincic M and Manferrari M: Molecular cytogenomic characterization of the murine breast cancer cell lines C 127I, EMT6/P and TA3 Hauschka. Int J Mol Sci 21: 4716, 2020.

9. Stoner GD, Kikkawa Y, Kniazeff AJ, Miyai K and Wagner RM: Clonal isolation of epithelial cells from mouse lung adenoma. Cancer Res 35: 2177-2185, 1975.

10. Kubicova E, Trifonov V, Borovecki F, Liehr T, Rincic M, Kosyakova N and Hussein SS: First molecular cytogenetic characterization of murine malignant mesothelioma cell line AE17 and in silico translation to the human genome. Curr Bioinform 12: 11-18, 2017.

11. Wolff E, Girod S, Liehr T, Vorderwülbecke U, Ries J, Steininger $\mathrm{H}$ and Gebhart E: Oral squamous cell carcinomas are characterized by a rather uniform pattern of genomic imbalances detected by comparative genomic hybridisation. Oral Oncol 34: 186-190, 1998.

12. Sy SM, Wong N, Lee TW, Tse G, Mok TS, Fan B, Pang E, Johnson PJ and Yim A: Distinct patterns of genetic alterations in adenocarcinoma and squamous cell carcinoma of the lung. Eur J Cancer 40: 1082-1094, 2004

13. Camps J, Mrasek K, Prat E, Weise A, Starke H, Egozcue J, Miró R and Liehr T: Molecular cytogenetic characterisation of the colorectal cancer cell line SW480. Oncol Rep 11: 1215-1218, 2004.

14. Rhode H, Liehr T, Kosyakova N, Rinčic M and Azawi SSH: Molecular cytogenetic characterization of two murine colorectal cancer cell lines. OBM Genet 2: 037, 2018.

15. Frattini A, Fabbri M, Valli R, De Paoli E, Montalbano G, Gribaldo L, Pasquali $\mathrm{F}$ and Maserati E: High variability of genomic instability and gene expression profiling in different HeLa clones. Sci Rep 5: 15377, 2015.

This work is licensed under a Creative Commons Attribution-NonCommercial-NoDerivatives 4.0 International (CC BY-NC-ND 4.0) License. 